\title{
Phagocytic activity and oxygen metabolism of peripheral blood granulocytes from rabbits experimentally infected with Trichophyton mentagrophytes
}

\author{
Katarzyna Wojcicka-Lorenowicz, Krzysztof Kostro, \\ Urszula Lisiecka, Bolesław Gąsiorek \\ Department of Epizootiology and Clinic of Infectious Diseases, Faculty of Veterinary Medicine, \\ University of Life Sciences in Lublin, 20-612 Lublin, Poland \\ kkostro@wp.pl
}

Received: May 11, 2017 Accepted: February 14, 2018

\begin{abstract}
Introduction: Phagocytic activity and oxygen metabolism of peripheral blood granulocytes from rabbits with experimental trichophytosis were assessed by flow cytometry. Material and Methods: Virulent species of T. mentagrophytes var. granulosum (Tm-K) isolated from rabbits with natural trichophytosis was used for experimental infection. The phagocytic activity of granulocytes was measured in whole blood by flow cytometry using the commercial Phagotest kit. Oxidative burst was measured in whole blood by flow cytometry using the commercial Bursttest kit. Results: It was found that rabbits were susceptible to infection with Trichophyton mentagrophytes under experimental conditions. The analysis of the phagocytic activity indices and oxygen metabolism of granulocytes in peripheral blood of infected rabbits showed that changes of the indices were connected with the progression and regression of the disease. A significant decrease in phagocytic activity and oxygen metabolism was observed during development of fungal lesions and it remained similar throughout the progress of the disease. The highest means of the percentage of activated and ingesting phagocytes and a significant increase in the mean fluorescence intensity (representing the number of ingested bacteria) were observed during spontaneous recovery. Therefore, the decrease or increase in the indices of phagocytic activity and oxygen metabolism of granulocytes from rabbits experimentally infected with T. mentagrophytes is somehow related to the progress of infection and suppressive activity of the fungus, whose elimination during recovery caused significant increases in investigated indices of non-specific cellular immunity. Conclusion: The results of the present investigation confirm that the mechanism of oxygen-dependent killing is crucial in infections caused by T. mentagrophytes.
\end{abstract}

Keywords: rabbits, Trichophyton mentagrophytes, phagocytic activity, oxygen metabolism, granulocytes.

\section{Introduction}

Trichophyton mentagrophytes, a highly contagious pathogen, is the main agent of ringworm aetiology in rabbits. Spores of $T$. mentagrophytes are very resistant to environmental factors and disinfectants. The spores could survive near one and a half year in animal enclosure and this feature essentially influences stationary prevalence of ringworm in plague-stricken area $(1,3,7,11,17,19,20,22)$. During the early stage of infection caused by dermatophytes the main mechanism of skin cellular non-specific immunity, which is involved in elimination of fungi, is phagocytosis. Fungal focus is infiltrated mainly by neutrophils whose activity is influenced by chemotactic factors such as complement fragment C3 or IL-8 released by keratinocytes (15). The neutrophils have killing mechanisms which are oxygen-dependent and oxygen-independent (defensins, cathepsin, lysosyme, elastase, azurocidin), having a strong inhibitory effect on the growth of fungi $(4,15)$. Small particles of the fungus (e.g. microconidia) are easily absorbed and destroyed in the phagolysosome by phagocytosis. The complement fragment C3 plays an important role in this process. The myeloperoxidase system of neutrophils exerts destructive effect on dermatophyte 
spores, even in the presence of catalase released by fungi, whose role is to prevent this phenomenon (15). On the other hand, the mycelium hyphae are surrounded by the neutrophils, which join together by means of lectin receptors and release fungicidal substances (mainly oxidising metabolites) into the direct surroundings $(4,15)$.

In the later stage of fungal infection, the main effector cells, which disable fungal penetration into deeper parts of skin, are macrophages. These cells have lectin receptors on their surface, directly binding special carbohydrates of the cellular wall or destroy them via surface receptor Fc IgG and complement fragment $\mathrm{C} 3$. Macrophages engulf and process fungal antigens and present them to $T$ cells in the presence of MHC II particles. Additionally, macrophages release cytokines which induce expression of adhesion molecules on endothelial cells of the capillary vessels (16).

The main objective of the present study was the analysis of the indices of phagocytic activity and oxygen metabolism of granulocytes from rabbits experimentally infected with $T$. mentagrophytes. The study also intended to define whether a decrease or increase in the indices is related to the progress of infection and suppressive activity of the fungus.

\section{Material and Methods}

Experimental animals. The study was performed on 16 New Zealand rabbits aged 10 weeks which came from a breeding farm free from ringworm. Animals were divided into an experimental group (group I) and a control group (group II). During the experiment the rabbits from both groups were fed full-portion of granulated fodder with the addition of coccidiostatics and water ad libitum. Group I consisted of eight rabbits experimentally infected with $T$. mentagrophytes. Before the experiment, hair samples were collected from various body areas for mycological testing. No sign of dermatophytes were demonstrated in any sample. In addition, intracutaneous skin test was performed in these animals. A refined glycoprotein fraction (Tm-GP) obtained from the strain T. mentagrophytes, according to Wołoszyn and Umiński (25) was used to perform skin tests. The allergen was administered intradermally at a dose of $0.2 \mathrm{~mL}(0.2 \mathrm{mg}$ protein concentration). The results were collected after 24,48 , and $72 \mathrm{~h}$ by assessing heat diameter and swelling. Skin test results were negative in all animals.

The virulent species of $T$. mentagrophytes var. granulosum $(\mathrm{Tm}-\mathrm{K})$ isolated from rabbits with natural trichophytosis was used for experimental infection (14). The initial examinations demonstrated that the $\mathrm{Tm}-\mathrm{K}$ species induced typical lesions in the form of fungal foci in animals infected with a dose of $10^{4} \mathrm{cfu} / \mathrm{mL}$, which was considered the lowest infective dose for rabbits. The rabbits were infected by rubbing the suspension into the shaved and slightly scarified skin for two successive days around the scapula, thighs on both sides, and back (in total, five areas). The daily dose, i.e. $5 \mathrm{~mL}$ of suspension, was divided into five portions and rubbed into the skin of each rabbit. Animals with experimental trichophytosis were under clinical observation to assess the dynamics of the disease process, time of regression of fungal lesions, and survival of fungal spores. The survival of T. mentagrophytes spores was evaluated by culturing the scrapings collected from the lesions in the Sabouraud medium with the addition of actidione $\left(27^{\circ} \mathrm{C}, 14\right.$ days).

Group II consisted of eight healthy rabbits from which hair samples were collected from various body areas for mycological testing. Skin tests were performed in the same way as in experimental group. No dermatophytes were observed in any sample. Skin test results were negative in all animals.

Phagocytosis assay. The phagocytic activity of granulocytes was measured by flow cytometry using the commercial Phagotest kit (Orpegen Pharma, Germany), according to the manufacturer's instructions. Heparinised peripheral blood $(100 \mu \mathrm{L})$ was incubated with $20 \mu \mathrm{L}$ of FITC-labelled heat-killed E. coli $(10 \mathrm{cfu})$ for $20 \mathrm{~min}$ at $37^{\circ} \mathrm{C}$, a negative control remained in the ice bath for $20 \mathrm{~min}$. At the end of the incubation, all the samples were placed in the ice bath in order to stop phagocytosis. A volume of $100 \mu \mathrm{L}$ of ice-cold Quenching Solution was added to each sample. The samples were mixed (by vortex mixer) for $2 \mathrm{~min}$ at $25^{\circ} \mathrm{C}$. Then, $3 \mathrm{~mL}$ of cold washing solution was added to each sample and centrifuged at $1,250 \mathrm{rpm}$ for $5 \mathrm{~min}$ at $4^{\circ} \mathrm{C}$. After two washing steps, the erythrocytes were removed with $2 \mathrm{~mL}$ of lysing solution added for $20 \mathrm{~min}$ at room temperature. The supernatant was discarded; $3 \mathrm{~mL}$ of cold washing solution was added, and then centrifuged at $1,250 \mathrm{rpm}$ for $5 \mathrm{~min}$ at $4^{\circ} \mathrm{C}$. DNA staining solution $(100 \mu \mathrm{L})$ was added and incubated in the ice bath for $10 \mathrm{~min}$. The samples were analysed by flow cytometry (EPICS XL, Beckman Coulter, USA) within $30 \mathrm{~min}$. The percentage of FITC positive cells and mean fluorescence intensity (representing the number of ingested bacteria) were measured, and the phagocytic index (percentage of positive cells $\mathrm{x}$ mean channel/100) was calculated after gating the granulocytes by size and granularity. Phagocytic activity was expressed as the mean fluorescence intensity (MFI) emitted by the cells which was proportional to the number of phagocytised bacteria.

Oxidative burst assay. Oxidative burst was measured in whole blood with flow cytometry using the Bursttest kit (Orpegen Pharma, Germany), according to the manufacturer's instructions. Heparinised whole blood $(100 \mu \mathrm{L})$ was incubated for $10 \mathrm{~min}$ at $37^{\circ} \mathrm{C}$ in the water bath with $20 \mu \mathrm{L}$ of $E$. coli suspension (E. coli opsonised), $20 \mu \mathrm{L}$ of PMA working solution (high control), $20 \mu \mathrm{L}$ of fMLP working solution (low control), and $20 \mu \mathrm{L}$ of washing solution (negative 
control). After incubation, $20 \mu \mathrm{L}$ of substrate solution was added to each sample and incubated for $10 \mathrm{~min}$ at $37^{\circ} \mathrm{C}$ in the water bath. The erythrocytes were removed by the addition of $2 \mathrm{~mL}$ of lysing solution to each tube for $20 \mathrm{~min}$ at room temperature. After incubation, the samples were washed in $3 \mathrm{~mL}$ of washing solution and centrifuged at $1,250 \mathrm{rpm}$ for $5 \mathrm{~min}$ at $4^{\circ} \mathrm{C}$. Then DNA staining solution $(200 \mu \mathrm{L})$ was added and incubated for $10 \mathrm{~min}$ in the ice bath. The samples were analysed by flow cytometry (EPICS XL, Beckman Coulter, USA) within $30 \mathrm{~min}$. Oxygen metabolism of granulocytes (percentage of activated cells) and phagocytic activity of granulocytes (expressed as the MFI) in peripheral blood were measured. The percentage of activated cells which were capable of producing oxygen metabolites was assessed on the basis of a model of DHR 123 (dihydrorodamine 123) into R123 (rhodamine123) conversion.

Statistical analysis. Data were compared by calculating means, standard deviations, and significance of differences between groups and successive determinations. The results were statistically analysed using the Student's $t$-test at significance levels 0.05 and 0.01 .

\section{Results}

Clinical observations and mycological test results. The clinical signs of infection in rabbits experimentally infected with $T$. mentagrophytes such as congestion, skin swelling, and peeling of epidermal layer at the inoculation site occurred between the $6^{\text {th }}$ and $8^{\text {th }}$ day of observation. Not until the $12^{\text {th }}$ to $14^{\text {th }}$ day yellow-grey coloured scabs of different thickness were formed. The blisters and the scabs covered all fungal foci and were always restricted to the infection sites only. Fungal foci were disappearing between the $30^{\text {th }}$ and $40^{\text {th }}$ day after the beginning of infection, which was manifested by skin exfoliation and coming off with the crust. Mycological examination proved that in each of infected rabbits $T$. mentagrophytes was present in inoculated sites between the $6^{\text {th }}$ and $22^{\text {nd }}$ day of infection. After 30 and 40 days, the results of inoculation tests from all rabbits were negative. In animals from control group no clinical signs of the disease were observed and the mycological examination findings were negative.

Granulocyte phagocytic activity results. Before the infection (day 0) granulocyte phagocytic activity in both groups was similar (Fig. 1a).

From the $8^{\text {th }}$ day, in the group of animals infected with $T$. mentagrophytes, the decline in percentage of phagocytes was statistically significant $(\mathrm{P}<0.05)$, with the lowest mean values on the $14^{\text {th }}$ day compared with both baseline values and control group values. After that period the percentage of phagocytic cells in rabbits infected with $T$. mentagrophytes was gradually and significantly increasing, with the highest mean values on the $40^{\text {th }}$ day. On this day the clinical signs of trichophytosis receded and the results of mycological examinations were negative.

Similarly, on the first day of investigations the MFI values in group I were comparable to controls (Fig. 1b).

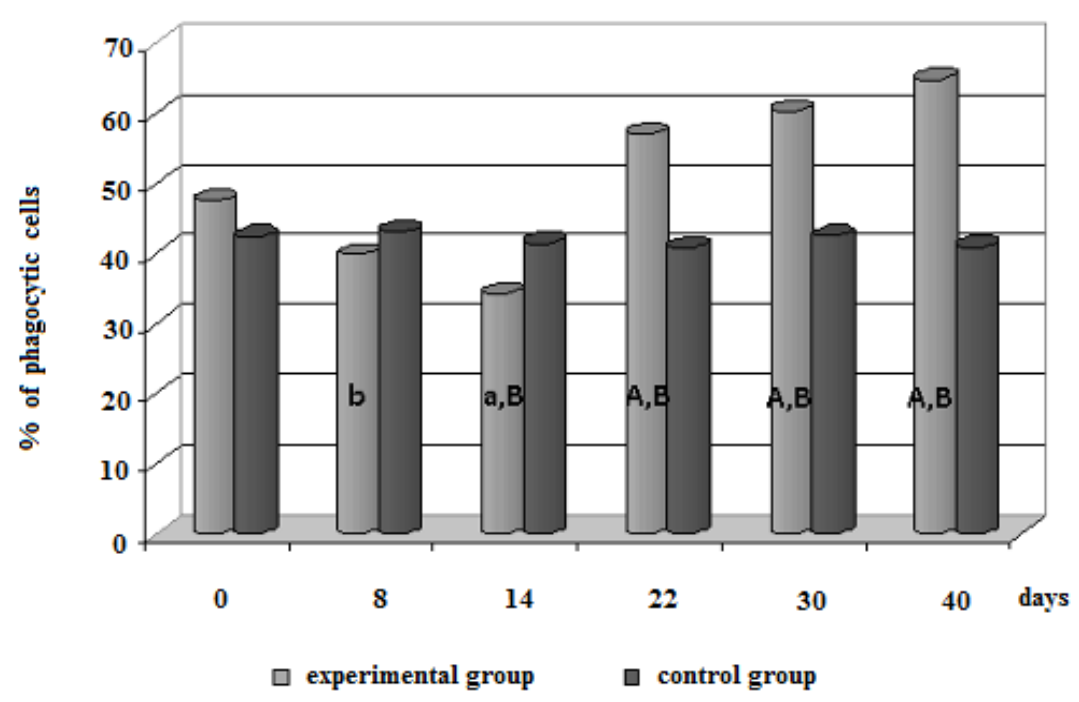

Fig. 1a. Phagocytic activity of granulocytes (mean percentage of phagocytic cells) from peripheral blood of rabbits experimentally infected with T. mentagrophytes

$\mathrm{A}-\mathrm{P}<0.01$ between experimental group (group I) and control group (group II)

$\mathrm{a}-\mathrm{P}<0.05$ between group I and group II

$\mathrm{B}-\mathrm{P}<0.01$ between individual examinations and day ,0"

$\mathrm{b}-\mathrm{P}<0.05$ between individual examinations and day , 0 ” 


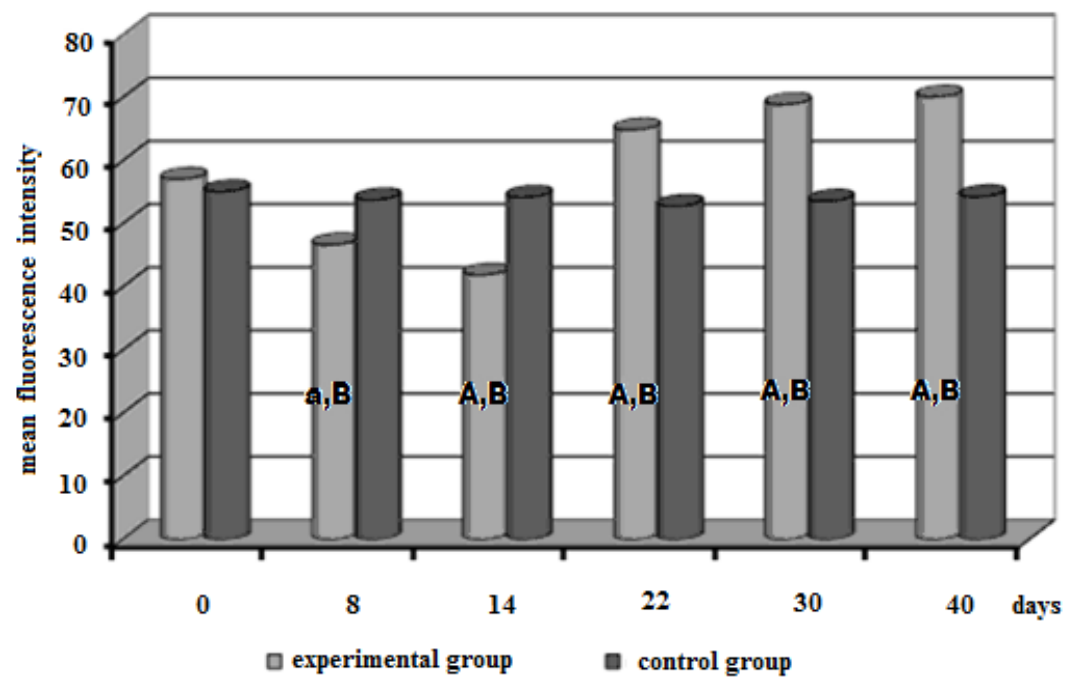

Fig. 1b. Phagocytic activity of granulocytes (mean fluorescence intensity) from peripheral blood of rabbits experimentally infected with T. mentagrophytes

$\mathrm{A}-\mathrm{P}<0.01$ between experimental group (group I) and control group (group II)

$\mathrm{a}-\mathrm{P}<0.05$ between group I and group II

$\mathrm{B}-\mathrm{P}<0.01$ between individual examinations and day ,0"

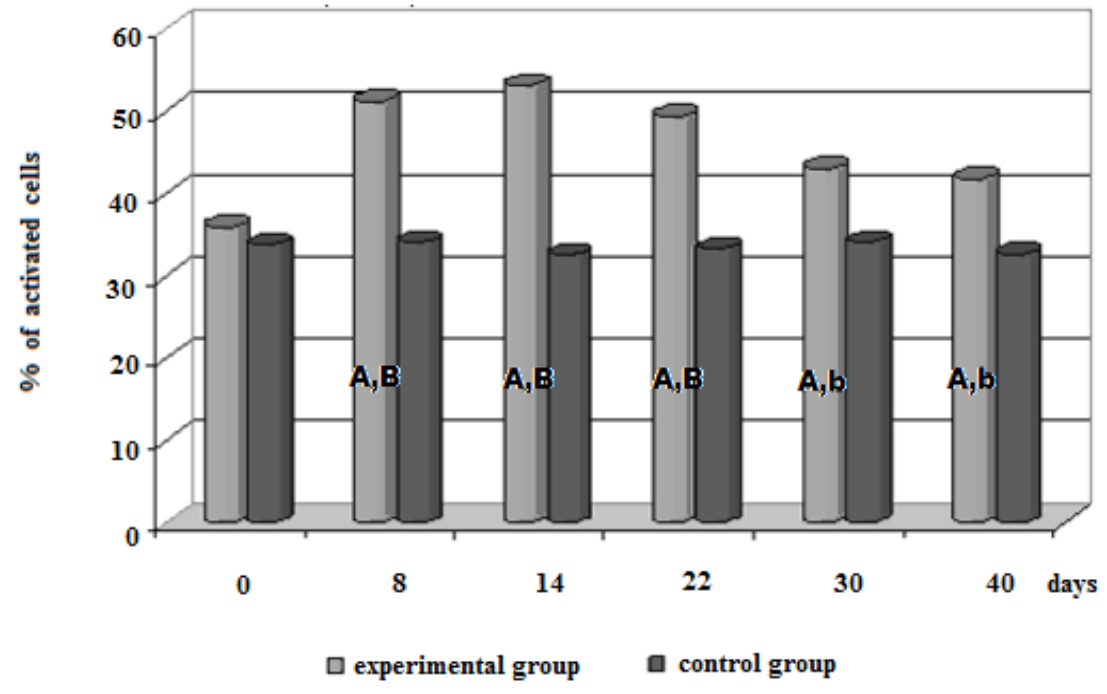

Fig. 2a. Oxygen metabolism of granulocytes (mean percentage of cells activated by E. coli) from peripheral blood of rabbits experimentally infected with $T$. mentagrophytes

$\mathrm{A}-\mathrm{P}<0.01$ between experimental group (group I) and control group (group II)

$\mathrm{b}-\mathrm{P}<0.05$ between individual examinations and day , 0 ",

$\mathrm{B}-\mathrm{P}<0.01$ between individual examinations and day ,0"

The MFI values determined on the $8^{\text {th }}$ and $14^{\text {th }}$ day after experimental infection with $T$. mentagrophytes (group II) were the lowest $(\mathrm{P}<0.01)$ in the total course of the experiment compared to baseline values and control values. At successive measurement points, the MFI was gradually increasing and at the final measurement was the highest. In rabbits from group II, the mean values of percentage of phagocytic cells remained at the level similar to the baseline values throughout the study. The MFI was also similar to the baseline values.

Granulocyte oxygen metabolism results. The data presented in Fig. 2a clearly show that the percentage of cells activated by $E$. coli was similar in control and investigated groups on the first day of investigation. 


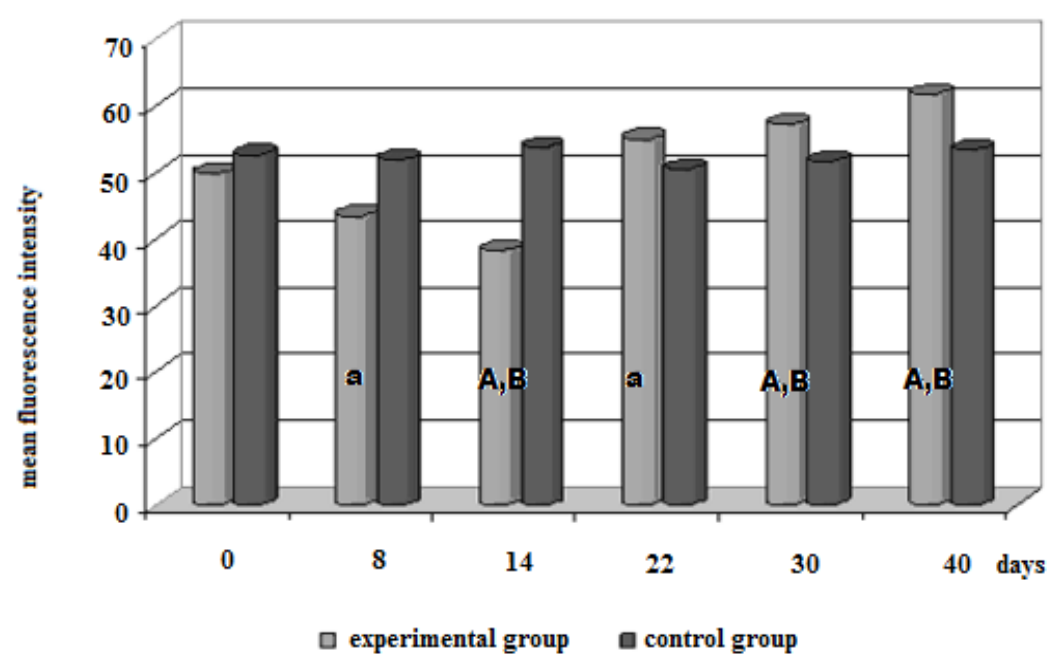

Fig. 2b. Oxygen metabolism of granulocytes (mean fluorescence intensity) after activation by E. coli) from peripheral blood of rabbits experimentally infected with T. mentagrophytes $\mathrm{a}-\mathrm{P}<0.05$ between experimental group (group I) and control group (group II) $\mathrm{A}-\mathrm{P}<0.01$ between group I and group II

$\mathrm{B}-\mathrm{P}<0.01$ between individual examinations and day ,0"

In rabbits experimentally infected with T. mentagrophytes (group I), significant $(\mathrm{P}<0.01)$ increase in the percentage of phagocytic cells occurred from the $8^{\text {th }}$ day and on the $14^{\text {th }}$ day during the full development of clinical symptoms of trichophytosis, the maximum indices of activated cells were noted. After that period a decrease in percentage of activated cells was observed in the experimental group, but until the end of the experiment mean values of activated cell percentage were significantly higher compared with the baseline value $(P<0.05)$ and controls $(P<0.01)$. Before the infection the values of the MFI were also similar in both groups (Fig. 2b).

In the rabbits experimentally infected with T. mentagrophytes, the lowest and statistically significant values of the MFI throughout the experiment were observed between the $8^{\text {th }}$ and $14^{\text {th }}$ day when the persistence of fungal lesions was also noted. From the $22^{\text {nd }}$ day in group I a gradual and statistically significant increase in the MFI was noted and on the $40^{\text {th }}$ day the highest values compared to the baseline value and control group values were recorded. In the rabbits from group II, the percentage of activated cells and the MFI values remained at the level similar to baseline values throughout the course of experiment.

\section{Discussion}

The present study demonstrated that rabbits are susceptible to experimental $T$. mentagrophytes infection. All animals in the experimentally infected group showed clinical signs manifested as thick scabs strongly connected with the skin. Fungal lesions receded after 40 days of infection, which was probably connected with the development of specific cellular immunity. The highest positive values of the leukocyte migration inhibition factor (LMIF) test and negative values of mycological findings in this period confirmed the regression of the disease (24). In the early stage of infection caused by dermatophytes, the first lines of defence are granulocytes, especially neutrophils. The flow cytometry method with the adapted Phagotest and Bursttest sets provided numerous valuable data concerning functional status of these cells. In our studies this method was applied to assess phagocytic and killing activity of rabbit granulocytes during experimental trichophytosis. The analysis of the indices of the phagocytic activity and oxygen metabolism in granulocytes of peripheral blood of rabbits infected with $T$. mentagrophytes shows that their changes were related to the course and regression of the disease. A significant decrease in phagocytic activity and oxygen metabolism of granulocytes was observed during the development of fungal lesions and was similar throughout the course of the disease. It particularly concerned a significant decrease in the MFI which is an index of phagocytosis intensity in individual cells. The highest means of the percentage of activated and ingesting phagocytes and significant increase in the MFI were observed during the spontaneous recovery. It could be assumed that a decrease or increase in phagocytic activity and oxygen metabolism indices may be somehow related to the progress of infection and suppressive interaction of the fungus, the elimination of which during recovery caused significant increases in investigated indices of non-specific immunity $(5,6,13,23)$. The suppressive effect on cellular non-specific antimycotic mechanisms is caused by mannans which are embedded in cell walls 
of dermatophytes $(2,8,9,10,12)$. The inhibiting role of these substances is probably blocking surface receptors of phagocytic cells $(4,12,15,21)$. It is possible that the observed disturbed granulocyte function in rabbits with experimental trichophytosis resulted from the lack of capability of indirect destruction of the fungi and ability to eliminate clinical signs in the first stage of infection caused by T. mentagrophytes. It is generally accepted that the efficient system of phagocytic cells is one of the basic mechanisms of non-specific cellular antimycotic immunity involved in the elimination of dermatophytes. Two different mechanisms are engaged in fungal spores destroyed by granulocytes: the first is connected with oxygen-dependent killing and the second mechanism is connected with enzymatic digestion in lysosomes $(10,15,18)$. The results of the present investigation confirm that the mechanism of oxygen-dependent killing is crucial in infections caused by $T$. mentagrophytes.

Conflict of Interests Statement: The authors declare that there is no conflict of interests regarding the publication of this article.

Financial Disclosure Statement: This research did not receive any specific grant from funding agencies in the public, commercial, or not-for-profit sectors.

Animal Rights Statement: The research was in compliance with Polish animal welfare regulations and approved by the Local Ethics Committee for Animal Experimentation of the University of Life Sciences in Lublin, Poland.

\section{References}

1. Banks K.L., Clarkson T.B.: Naturally occurring dermatomycoses in rabbit. J Am Vet Med Assoc 1967, 151, 926-929.

2. Cabrera R.M., Blake J.S., Dahl M.V.: Inhibition of keratinocyte proliferation by a mannan glycoprotein isolated from Trichophyton rubrum. J Invest Dermatol 1991, 96, 616-621.

3. Cafarchia C., Weigl S., Figueredo L.A., Otranto D.: Molecular identification and phylogenesis of dermatophytes isolated from rabbit farms and rabbit farm workers. Vet Microbiol 2012, 154, 395-402.

4. Calderon R.A., Hay R.J.: Fungicidal activity of human neutrophils and monocytes on dermatophyte fungi, Trichophyton quinckeanum and Trichophyton rubrum. Immunology 1987, 61, 289-295.

5. Dahl M.V.: Suppression of immunity and inflammation by products produced by dermatophytes. J Am Acad Dermatol 1993, 28, 19-23.

6. Davies R.R., Zaini F.: Trichophyton rubrum and the chemotaxis of polymorphonuclear leukocytes. J Med Vet Mycol 1984, 22, 65-71.
7. Ergin C., İlkit M., Gök Y., Özel M.Z., Çon A.H., Kabay N., Söyleyici S., Döğen A.: Fourier transform infrared spectral evaluation for the differentiation of clinically relevant Trichophyton species. J Microbiol Methods 2013, 93, 218-223.

8. Grando S.A., Herron M.J., Dahl M.V.: Binding and uptake of Trichophyton rubrum mannan by human epidermal keratinocytes: a time course study. Acta Dermatol Venerol 1992, $72,273-276$

9. Grando S.A., Hostager B.S., Herron M.J.: Binding of Trichophyton rubrum mannan to human monocytes in vitro. J Invest Dermatol 1992, 98, 876-880.

10. Gregurek-Novak T.: Effect of infection with Trichophyton mentagrophytes varietas interdigitale on phagocytosis in humans. Eur Acad Dermatol Venereol 2004, 18, 160-163.

11. Hagen K.W.: Ringworm in domestic rabbits: oral treatment with griseofulvin. Lab Anim Care 1969, 19, 635-638.

12. Hau C., Tada Y., Kanda N., Watanabe S.: Immunoresponses in dermatomycoses. J Dermatol 2015, 42, 236-244.

13. Kostro K., Gliński Z.: The kinetics of the immune response to natural trichophytosis in arctic foxes. Folia Vet 2000, 44, $106-111$.

14. Kostro K., Gliński Z., Wojcicka-Lorenowicz K., Gacek L., Krakowski M.: Allopevac vaccine in prophylactics and controlling trichophytosis in rabbits. Med Weter 2000, 56, 816-821.

15. Kostro K., Gliński Z., Wojcicka-Lorenowicz K.: Immunological responses in dermatomycoses of animals. Med Weter 2001, 57, 709-714.

16. Kostro K., Gliński Z., Wojcicka-Lorenowicz K., NozdrynPłotnicki Z.: Antiinfectious immunity of skin. Med. Weter 2002, $58,655-660$

17. Kraemer A., Mueller R.S., Werckenthin C., Straubinger R.K., Hein J.: Dermatophytes in pet guinea pigs and rabbits. Vet Microbiol 2012, 157, 208-213.

18. LeibundGut-Landmann S., Wuthrich M., Hohl T.M.: Immunity to fungi. Current Opinion Immunol 2012, 24, 449-458.

19. Mesquita J.R., Vasconcelos-Nóbrega C., Oliveira J., Coelho C., Vala H., Fratti M., Arabatzis M., Velegraki A., Monod M.: Epizootic and epidemic dermatophytose outbreaks caused by Trichophyton mentagrophytes from rabbits in Portugal 2015. Mycoses 2016, 59, 668-673.

20. Symoensa F., Joussonb O., Planarda C., Frattic M., Staibd P., Mignone B., Monod M.: Molecular analysis and mating behaviour of the Trichophyton mentagrophytes species complex. Int J Med Microbiol 2011, 301, 260-266.

21. Swan J.W., Dahl M.V., Coppo P.A., Hammerschmidt D.E.: Complement activation by Trichophyton rubrum. J Invest Dermatol 1983, 80, 156-158.

22. Szili M., Kohalmi I.: Endemic Trichophyton mentagrophytes infection of rabbit origin. Mycosen 1981, 24, 412-420.

23. Wojcicka-Lorenowicz K., Kostro K.: Flow cytometry evaluation of phagocytic activity and oxygen metabolism of granulocytes in peripheral blood of rabbits with natural trichophytosis. Bull Vet Inst Pulawy 2008, 52, 555-560.

24. Wojcicka-Lorenowicz K., Kostro K., Taszkun I.: Specific cellmediated immune responses in rabbits naturally and experimentally infected with Trichophyton mentagrophytes and in immunised animals. Bull Vet Inst Pulawy 2013, 57, 329-333.

25. Wołoszyn S., Umiński M.: Serological and allergic activity of native and pure trichophytin. Med Weter 1985, 41, 394-398. 